\title{
Industry-University-Research Cooperation in Professional Translation Teaching
}

\author{
Qianqian Qu \\ School of Foreign Languages \\ Shaanxi University of Chinese Medicine \\ Xianyang, Shaanxi 712046, China
}

\begin{abstract}
This paper analyzes the current status of language service industry, professional translation teaching and the existing problems. The purpose of this paper, correspondingly, aims to make some explorations for translation professionalization in universities where the traditional translation teaching cannot adapt to the demanding needs of the language service industry and the real-world applications. Based on the analysis of the market-oriented and technology-based industry, this paper puts forward the corresponding professional teaching objectives and focuses prominently on approaches to professional translation teaching, that is, cooperate with industry experts to conduct industry-university-research cooperation and professional teacher training to better stimulate students' motivation.
\end{abstract}

Keywords-Industry-University-Research

Cooperation; Professional translators; Market-oriented; Translation teaching

\section{INTRODUCTION}

As an academic concept, language service has received unprecedented attention since it was proposed in 2005. Some researches concerning language services industry has been done in recent years at home and abroad. Yubo Wang and Xiangnong $\mathrm{Li}$ put forward in his article Integration of Language Service and " Internet + " that the so-called" language service "refers to the behavior or activity of a language or dialect holder providing help to the language or dialect demand object with the medium of that language or dialect [1] . Li also distinguished between gratuitous language services, such as education for primary and secondary school students, and language services in business, which form the language industry once the scale is established. Language, language resources and language services are complementary to each other. Therefore, language service, namely language resource service, is an important economic resource that serves the society and the public. Developing language resources, developing language economy and providing language services can provide impetus for social and economic development. Xianle Li pointed out in his paper Reflections on Several Problems of Language Service Research[2] that language service includes two categories: language service includes professional language service and industrial language service. The former mainly includes language translation service and language training service. The latter takes language as a tool of service, such as language service in catering, medical care, finance and other industries. Industry language service does not provide language products, but if the language service is absent in the whole industry service, it is incomplete, or even cannot be carried out.

The purpose of this study was to analyze and point out the current status and the necessity of teaching of translation cooperated with language service industry; to analyze the problems existing in their cooperation and to seek effective approaches of cooperation with language service industry in teaching practice of translation based on use of language service APP and realizing professionalization of translation talent cultivation.

\section{CURRENT STATUS OF LANGUAGE SERVICE INDUSTRY AND PROFESSIONAL TRANSLATION TEACHING}

\section{A. Fast growth of Language service industry in recent years}

As a newly formed modern service, language service industry in China becomes one of the most dynamic economic growth points. Language service business provided an annual output value up to 260 billion RMB by the year 2015 , and a massive increase in 2017 by $19.7 \%$ among which, Chinese translation service gains steady growth due to the increasing needs of the markets. It mainly includes the following business scope: translation, interpretation, document typesetting, consulting, language training service, localization services, letters and dubbing, machine translation and post-translation editing, technical collaboration, translation tools and software development, covering various fields, namely, foreign trade, cultural tourism and communication, international conference, law, chemical energy, machinery manufacturing, construction, etc. Language service industry has created a market providing $r$ more than a million jobs. However, there still exist a massive need of high-qualified professional talents who will meet the fast development of technologies and information.

This paper is supported by the research project of Shaanxi Administration

of Traditional Chinese Medicine (Shaanxi TCM Culture Study: Academic

Development Study on Chang'an Medical Schools, No. ZCMS007). 


\section{B. Development of market-oriented Professional Translation Teaching}

Traditional translation teaching and study based on language competence and translation theory and practice cannot meet the fast development of translation technologies and language service industry's requirements in such an internet+ and information explosion era. Internet resources, computer technologies and translation software and Apps are combined together to form a new professional translation model. Therefore, translation teaching scopes should keep up with these changes and enlarge from the traditional way to a more comprehensive and market-oriented way. Specifically speaking, professional translation teaching pays more attention to qualified translation skills, skilled application of translation tools and post-translation editing, awareness of cross-cultural communication ability and familiarity of translation operation process.

Specifically speaking, market-oriented professional translation teaching provides following professional training in:

- Methods of professional translation skills.

- Technology-application in professional translation, such as translation tools and on-line translation software.

- Tactics to attract clients and make more profits for enterprises.

- Processes to complete translation tasks and posttranslation editing

- eAppropriate attitude and cross-cultural communication abilities.

III. REQUiRED ABILITIES FOR PROFESSIONAL TRANSLATION TALENTS AND THE CORRESPONDING TEACHING OBJECTIVES

\section{A. Required abilities for professional translation talents}

The core of language service industry is language translation technology and content transformation, supported by information technology, Internet, project management technology, featuring global collaboration, cross-local culture, continuous content upgrading, promoting internationalization of enterprises and industries, and product localization as the service objectives. From this statement, it is clearly conveyed that no matter internationalization or localization, it is closely related with translation and professional translators who play an indispensable role in language service industry. The following three abilities are required for professional translation talents:

\section{1) Basic translation competence}

Basic translation competence refers to the basic language cognitive ability, including intuition, concept, inference, analysis, analogy, logical reasoning, prediction, association, imagination, comparison, information processing, etc.; language competence, including knowledge of vocabulary, syntax, grammatical attainments, semantic structure, pragmatic relevance, expression, rhetoric, style, and cultural awareness , and so on; communication ability, namely, those skills acquired through practices such as translation methods, translation strategies and their suitable usage in context; the knowledge of social background, communication purpose and the translators' adaptability, creation and their strain capacities. These elements are the primary requirements for a qualified translator or interpreter.

\section{2) Translation technology competence}

Translation technology competence refers to translator's ability to use and operate machine translation, translation software, online dictionaries translation tools, especially computer-assisted translation tools, such as glossary, corpus and other translation on-line tools. Those translation technologies are the main training contents for enterprises and for high-quality translation talents, in other words, application of translation technologies is the core competence for translators in such changing times. In the Internet age, the influence of computer technology has become an integral part of teaching and learning, so it also changes the form of traditional assessment to electronic forms such as computermediated communication[3]. With the development of globalization and information, traditional translation mode cannot keep up with the demanding needs of the language service market, hence corresponding translation teaching mode should be adapted to the market's needs.

\section{3) Cross-cultural communication competence}

Generally speaking, the intercultural bilingual talents with solid ability of translation are required to have the following three primary abilities: familiar with the knowledge of Chinese culture, skilled bilingual or multilingual application ability, and strong awareness of language service. According to the author's summer questionnaire and feedback statistics in 2017, for students in Chinese medical schools, most of them acquire the first ability, but there is still a shortage of talents with the second and the third ability. For teachers in traditional Chinese medicine colleges and universities, the number of teachers with the first and third ability is large, while the number of teachers with the second ability is rare. For overseas students in Chinese medicine universities, their first and third abilities are much weaker than those of domestic students, while the second abilities are relatively stronger.

Take traditional Chinese medicine as an example. Currently, it has been widely spread around the world and its products have been exported to 160 countries and regions. However, in countries along the new silk road, the development of language service industry still faces many barriers and obstacles. One of the very realistic reasons for this phenomenon is the shortage of professional translators in the trade of specific trade, for example, Chinese herbs. Many practitioners of TCM are technically proficient, but have no language foundation. Therefore, as professional translators cultivated by some specific fields, their awareness of language serve must be strengthened in order to meet the demands of the language service market. 


\section{B. Corresponding teaching objectives}

From the above analysis, it is easily seen that the market needs decide the direction of talent cultivation, thus professional translators, to be specific, MTI education should base its teaching objective on market-oriented language service industry.

\section{1) Talent cultivation model to be improved}

Firstly, focus should be paid on talent cultivation model, that is, to establish a market-oriented language service talent cultivation mechanism. Currently, there exist 206 universities that have the qualifications for MTI courses which mainly foster translation and interpretation talents for language service market, however, the market still has the demanding necessity for more qualified talents who can handle professional translation technologies and deal with multilingual translation tasks. It is obvious that there is a gap between talents cultivated by universities and the actual need of the market. Therefore, it proposes an issue for both teachers and researches to reflect: how to adjust school's professional talent cultivation model to the market. Some researchers have already done a lot in this respect. UMoh Nyong Ikpe [4] proposed and emphasized Students Industrial Work Experience Scheme (SIWES) in his paper which is an effective approach to train students in technologically literate workforce who can provide them with a professional ability before they graduate from universities. This will no doubt lead to the integration of translation technology programs into the educational discipline using various skills and techniques to enhance the quality of learning and teaching which assist the students with realistic experiences in the application of translation technologies.

\section{2) Introduction of applied and diverse translation} technology courses

Today, with the rapid development of modern language service industry, universities qualified with MTI should think more concerning how to cultivate high-quality professional translators with basic translation competence, translation technology competence and interdisciplinary and intercultural communication talents. By changing the traditional translation mode into market-oriented translation talents training mode, the whole translation curriculum should increase the proportion of non-literary translation courses, in view of the demand for more professional translators in the industry, combined with characteristic disciplines, and introduce science and technology translation, news translation, tourism translation and legal translation by highlighting application-oriented and marketoriented translation talents cultivation mode.

\section{APPROACHES TO THE EDUCATION FOR PROFESSIONAL TRANSLATION TALENTS}

\section{A. The cooperation of Industry-university-research based on school-enterprise cooperation}

According to Wikipedia, cooperative industrial education is a structured method of combing classroom-based education with practical work experience. It is newly developed mode among employers, students and school faculty. Language service enterprises provide workplace employment opportunities and learning experiences which may facilitate school-to-work transition, service learning and experiential learning initiatives. Meanwhile, this cooperation program will definitely promote professional teaching tailored towards meeting the objectives of professional translation talents which include enabling students:

- To have the translation skills and competencies required by language service industry;

- To apply translation theories and basic translation competence acquired in class into real workplaces;

- To establish proper attitudes and personal qualities and professional morality necessary for adjustments to employment situations;

- To guide students for post-editing processes after their translation assignments.

As for our school, the school-enterprise cooperation is overwhelmingly practical because of its medical specialty combined closely with translation for cultural communication among the countries along the Belt and Road. Firstly, it is planned to set up an Internet network platform for traditional Chinese medicine culture communication in Shaanxi University of Chinese Medicine and try to complete a multilingual web site and use machine assisted translation equipment, etc., to open up a variety of training channels for bilingual talents teaching beyond the classroom. Secondly, many international students along the route of "The Belt and Road" choose Shaanxi university of Chinese Medicine as their ideal places to study Chinese traditional culture, traditional Chinese medicine acupuncture and moxibustion, massage and other traditional Chinese medicine treatment programs. Their professional study here is combined with TCM professional translation. After graduation, many of them make use of their language advantage and apply the technology of TCM constantly in their own country in many ways, continuously spreading TCM culture all over the world. Some special courses are proposed to set up, such as "TCM bilingual health preservation and marketing", "TCM health preservation and cross-cultural communication", "TCM culture and bilingual tourism management", etc. in order to speed up the effective integration between disciplines, training TCM interdisciplinary talents.

\section{B. Professional faculty training in translation teaching}

The fast development of language service industry and demanding market requirements challenge academic teaching faculty to turn their translation teaching to be market-oriented and technology-based. Some academic teachers, however, disconnect their translation teaching from the realistic applications. Therefore, cooperative teaching between academic teaching faculty and industry experts is considered to be one viable approach to bridging the divide between theory and industry practice[5] In this way, the academic faculty can learn from the practical knowledge, experiences and resources that the experts may offer[6], meanwhile the students in classroom study are available to massive industry cases and professional translation processes and operations.

Professional faculty training items include: 
- To help students establish a PC environment under effective control;

- To develop the skills to use word-processing and translation-related software;

- To help students to get familiar with corpus, translate memory library and glossary, and apply these special knowledge to professional practice;

- To carry out machine translation and computer-assisted courses to help students master at least one of the mainstream machine translation tools;

- To introduce basic knowledge of project management to students and introduce translation project teaching into class.

\section{CONCLUSION}

In a word, professional translation talents who play actively in enterprises and real-world language service market demand for connection between academic translation study and schoolenterprise cooperation. Teachers, therefore, have more responsibilities in classroom to accelerate the integration of academic-industry cooperative teaching and focus on constantly modifying their teaching contents related to the market and to the students' professional translation competencies, especially under the background of "the Belt and Road" initiative which is an effective way to accelerate cultural communication among different countries and regions. Although the industry experts grasp more practical knowledge concerning professional translation, they may not have adequate teaching skills to motivate student learning. Hence, the university plays a significant role in providing supportive system by providing technology-based facilities and equipment which are keeping up with the industry. The professional faculty also plays a significant role in researching relevant information and learning from the industry experts who provide faculty and student training curriculum. Through these approaches, professional translation teaching is expected to achieve better teaching effects.

\section{REFERENCES}

[1] Yubo Wang, Xiangnong Li, Integration of language service and " Internet + ", Journal of Centrual China Normal University(Human and Social Sciences), Vol.55, 2016,pp. 353-368.

[2] Xianle Li, Reflections on the problems of language-service research, Journal of Yunnan Normal University, Vol.50, 2018, pp.16-24.

[3] Raveewan Wanchid, Valaikorn Charoensuk, The effects of paper-based portfolios and weblog-based electronic portfolios on limited English proficiency students in writing for service industry course. English language teaching, Vol.8, 2015,p. 131-145.

[4] UMoh Nyong Ikpe, Stephen Bepeh Undie, Business Education, Industry Cooperation and Technologies, Joural of Education and practice, Vol.5, 2014, pp. 23-30.

[5] Lyyia Feng, Min-huei Chiang, Making sense of academia-industry cooperative teaching, Journal of Hospitality, Leisure, Sport and Tourism Education, Vol.16, 2015, pp.43-47.

[6] Phelan,K.V., Mejia,C., \& Hertzman,J., The industry experience gap: hospitality faculty perceptions of the importance of faculty industry experience, Journal of Hospitality and Tourism Education, Vol.25, 2013 pp.123-130. 